\title{
Digestibilidade de Duas Fontes de Amido e Atividade Enzimática em Coelhos de 35 e 45 Dias de Idade 1
}

\author{
Fábio Luiz Buranelo Toral ${ }^{2}$, Antonio Claudio Furlan ${ }^{3}$, Cláudio Scapinello ${ }^{3}$, \\ Rosane Marina Peralta ${ }^{4}$, Denise Fontana Figueiredo ${ }^{5}$
}

RESUMO - Os experimentos foram conduzidos para avaliar a digestibilidade ileal (CDILEAL) e total (CDTOTAL) do amido e a atividade das enzimas amilase (ATAM) e maltase (ATMAL) em coelhos de 35 e 45 dias alimentados com amido proveniente do milho ou da raspa de mandioca. Em cada ensaio foram utilizados 20 coelhos da raça Nova Zelândia Branco, sendo dez machos e dez fêmeas, alojados individualmente em gaiolas de arame e distribuídos em um delineamento inteiramente casualizado. Ao final do período experimental, os animais foram abatidos para retirada de uma amostra do conteúdo digestivo de uma porção do jejuno e do íleo. Os CDILEAL e CDTOTAL do amido da raspa de mandioca $(59,25 \pm 1,38 \% \mathrm{e} 99,89 \pm 0,04 \%$, respectivamente $)$ foram superiores ao do milho $(54,21 \pm 1,51 \% \mathrm{e} 99,21 \pm 0,05 \%$, respectivamente). O CDTOTAL dos animais com 45 dias de idade foi superior ao dos com 35 dias $(99,75 \pm 0,04 \%$ vs $99,35 \pm 0,05 \%)$. A ATAM, no conteúdo do jejuno e do íleo, foi maior nos animais com 45 dias $(0,952 \pm 0,118 \mathrm{mmol}$ de glicose $/ \mathrm{mg} / \mathrm{min}$ e $0,647 \pm 0,093 \mathrm{mmol}$ de glicose/ $\mathrm{mg} / \mathrm{min}$, respectivamente) do que nos de $35(0,469 \pm 0,111 \mathrm{mmol}$ de glicose $/ \mathrm{mg} / \mathrm{min}$ e $0,375 \pm 0,088 \mathrm{mmol}$ de glicose $/ \mathrm{mg} / \mathrm{min}$, respectivamente). A ATMAL foi maior nos animais alimentados com raspa de mandioca do que nos que receberam milho $(0,061 \pm 0,007 \mathrm{mmol} \mathrm{de}$ glicose $/ \mathrm{mg} /$ $\min$ vs $0,032 \pm 0,007 \mathrm{mmol}$ de glicose $/ \mathrm{mg} / \mathrm{min}$ ). Conclui-se que o amido da raspa de mandioca é mais digestível que o do milho, e o sistema enzimático dos coelhos com 35 dias de idade ainda não está suficientemente desenvolvido para que ocorra otimização da digestão do amido.

Palavras-chave: amilase, maltase, milho, raspa de mandioca

\section{Digestibility of Two Starch Sources and Enzymatic Activity of 35 and 45 Days Old Rabbits}

\begin{abstract}
The research was carried out to evaluate the ileal (ILEALDC) and total (TOTALDC) digestibility of the starch and the activity of the enzymes amylase (ACAMY) and maltase (ACMAL) in rabbits of 35 and 45 days old, fed with starch from the corn or cassava. In each assay $20 \mathrm{New}$ Zealand White rabbits were used, being ten males and ten females, housed individually in wire cages and distributed in an entirely random arrange. At the end of the experimental period, the animals were killed for retreat a sample of the digestive content of a portion of the jejunum and ileum. ILEALDC and TOTALDC of the starch from cassava $(59.25 \pm 1.38 \%$ and $99.89 \pm 0.04 \%$, respectively) were higher than starch from corn ( $54.21 \pm 1.51 \%$ and $99.21 \pm 0.05 \%$, respectively). TOTALDC of the animals at 45 days old was higher than animals at 35 days old $(99.75 \pm 0.04 \%$ vs $99.35 \pm 0.05 \%)$. ACAMY in the jejunum and ileum contends was higher in the animals at 45 days old $(0.952 \pm 0.118 \mathrm{mmol}$ glucose $/ \mathrm{mg} / \mathrm{min}$ and $0.647 \pm 0.093 \mathrm{mmol}$ glucose $/ \mathrm{mg} / \mathrm{min}$, respectively) than 35 days old $(0.469 \pm 0.111$ $\mathrm{mmol}$ glucose $/ \mathrm{mg} / \mathrm{min}$ and $0.375 \pm 0.088 \mathrm{mmol}$ glucose $/ \mathrm{mg} / \mathrm{min})$. ACMAL was higher in animals fed cassava than corn $(0.061 \pm 0.007 \mathrm{mmol}$ glucose $/ \mathrm{mg} / \mathrm{min}$ vs $0.032 \pm 0.007 \mathrm{mmol}$ glucose $/ \mathrm{mg} / \mathrm{min}$ ). It can be concluded the starch from cassava is more digestible than starch from corn, and the enzymatic system of the rabbits with 35 days old are not still sufficiently developed so that it happens the highest starch digestion.
\end{abstract}

Key Words: amylase, cassava, corn, maltase

\section{Introdução}

Com relação aos processos de digestão, muitos autores comparam o coelho a outros monogástricos. Entretanto, o significativo volume relativo do ceco, apresentando um importante processo de degrada- ção de componentes da fibra, o hábito da cecotrofia, além das diferenças de funcionamento do trato digestivo, como a separação de partículas do conteúdo digestivo no colo proximal, representam particularidades que limitam esta comparação (Gidenne, 1996).

\footnotetext{
1 Projeto de Iniciação Científica PIBIC-CNPq/UEM.

2 Zootecnista, Aluno do curso de Pós-Graduação em Zootecnia (Genética e Melhoramento Animal) da Faculdade de Ciências Agrárias e Veterinárias - Universidade Estadual Paulista, Rod. Paulo Donato Castellane s/n, CEP: 14884-900. Jaboticabal - SP. E.mail: flbtoral@hotmail.com

${ }^{3}$ Zootecnistas, Professores do Departamento de Zootecnia da Universidade Estadual de Maringá, Av. Colombo 5790, CEP: 87020-900. Maringá, PR. E.mail: acfurlan@uem.br; cscapinello@uem.br

${ }^{4}$ Farmacêutica, Professora do Departamento de Bioquímica da UEM. E.mail: rmperalta@uem.br

5 Zootecnista, Aluna do curso de Pós-Graduação em Zootecnia (Produção Animal) da FCAV - UNESP, bolsista do CNPq E.mail: denisefigueiredo@hotmail.com
} 
Em adição às particularidades da fisiologia cecal dos coelhos, pequenas variações na composição química do conteúdo digestivo que passam a esta porção do trato digestivo podem ser responsáveis por distúrbios digestivos. Esses problemas ocorrem principalmente em coelhos em crescimento e, mais particularmente, próximo ao período de desmama.

A atividade de microorganismos no ceco tem um papel importante na nutrição e saúde dos coelhos e mudanças na composição química da dieta, tanto quantitativa como qualitativamente, podem modificar as condições, em especial de $\mathrm{pH}$ e motilidade do trato digestivo, com conseqüente alteração nos processos de digestão e fermentação cecal.

Embora poucos trabalhos tenham sido publicados, estudos sobre atividade enzimática ligada aos processos de digestão do amido no intestino delgado mostram que os coelhos até seis a sete semanas de idade não apresentam a produção de amilase pancreática ainda bem estabelecida e, em função disto, o amido dietético pode, muitas vezes, não ser completamente hidrolisado no intestino delgado, aumentando o seu fluxo para o ceco, podendo este ser a causa original dos distúrbios digestivos.

Deve-se considerar que não apenas o volume de amido e a baixa atividade de enzimas amilolíticas no intestino delgado em coelhos jovens, mas também a origem do amido fornecido na dieta, bem como o processamento do mesmo, têm grande influência no processo digestivo, em especial no intestino delgado, de coelhos jovens (Blas \& Gidenne, 1998).

O amido compreende a maior reserva de polissacarídeos de plantas verdes e é, provavelmente, o segundo mais abundante carboidrato na natureza; é encontrado em grãos, raízes e tubérculos (Blas \& Gidenne, 1998).

Em seu estado natural existe como um complexo altamente organizado de amilose-amilopectina, na forma granular. Os grânulos de amido diferem em suas aparências, tamanho e propriedades, de acordo com a espécie vegetal. O interior do grânulo é composto de regiões cristalinas e amorfas alternadas. A destruição desta organização é a base da gelatinização, visto que a amilose e a amilopectina, em sua condição natural, não são prontamente acessíveis à ação da amilase no processo de digestão (Rooney \& Pflugfelder, 1986).

Segundo Lehninger et al. (1995), a amilose consiste basicamente de uma cadeia longa e linear de moléculas de D-glicose unidas por ligações $\alpha 1-4$ e a amilopectina, uma cadeia longa e ramificada com ligações $\alpha 1-4$ e $\alpha 1-6$. Contudo, Blas \& Gidenne (1998) afirmam que a estrutura polimérica é mais complicada e a estrutura primária não é ainda bem entendida. Tem-se verificado que algumas moléculas de amilose apresentam diversas ramificações.

A proporção relativa de amilose e amilopectina varia consideravelmente de acordo com a origem da planta. O amido dos cereais contém de 20 a $25 \%$ de amilose, ao contrário dos legumes onde este percentual oscila entre 25 e $65 \%$.

O amido do milho apresenta $28 \%$ de amilose e $72 \%$ de amilopectina, enquanto que o amido da mandioca 17 e 83\%, respectivamente (Swinkels, 1985).

Segundo Rooney \& Pflugfelder (1986) e Kabir et al. (1998), a digestibilidade do amido é, em geral, inversamente proporcional ao seu conteúdo de amilose, mas, Zhou \& Kaplan (1997) observaram em ratos que o amido de batata ( $70-75 \%$ de amilopectina) teve digestibilidade inferior ao amido do milho ( $70 \%$ de amilose).

As enzimas responsáveis pela digestão do amido são as amilases ( $\alpha 1-4$ glicano hidrolases). No processo digestivo a a-amilase (endoamilase) hidrolisa as ligações $\alpha 1-4$ glicosídicas dentro da molécula do amido, gerando maltose e dextrina ramificada e linear. A $\beta$-amilase e glicoamilase (exoamilases) atacam os resíduos de glicose terminais, produzindo maltose e glicose, respectivamente. Finalizando o processo, as amiloglicosidases intestinais hidrolisam as dextrinas, produzindo glicose (Moreira, 1993).

De acordo com Blas \& Gidenne (1998), a digestão do amido é primariamente afetada pela idade do coelho, pelo nível e origem do amido da dieta. Alguns outros fatores, tais como o processamento e uso de enzimas exógenas podem também influenciar.

Para coelhos adultos, os dados de digestibilidade em diferentes estudos mostram que as perdas fecais de amido são muito baixas em todos os casos. Ao contrário, coelhos com seis semanas de idade não apresentam a amilase pancreática bem estabelecida, 0 que provoca aumento do teor de amido nas fezes. Blas et al. (1994) verificaram que, quando o conteúdo de amido da dieta aumentou de 16 para $25 \%$, o conteúdo de amido ileal de coelhos jovens dobrou, enquanto o nível cecal alcançou $6 \%$.

As perdas fecais de amido do milho são grandes, principalmente para coelhos jovens, e isto ocorre em função, principalmente, do incompleto desenvolvimento do sistema enzimático e da resistência do amido do milho aos processos de digestão intestinal. 
Assim, a estrutura do endosperma das sementes de milho e a resistência à moagem são vistas como os principais fatores que explicam sua baixa disponibilidade. Este efeito é minimizado quando da utilização do amido purificado.

Heckman (1972) verificou que dietas contendo mais que $20 \%$ de amido proveniente da batata crua provocaram alto conteúdo de água nas fezes, sugerindo como sendo o primeiro estágio de diarréia. Gidenne (1995) também observou alta incidência de diarréia em coelhos alimentados com dietas, contendo gluco-oligossacarídeos, os quais forneceram glicose após hidrólise por bactérias fecais.

Gidenne \& Perez (1993) observaram que os amidos provenientes da cevada e amido de milho purificado foram completamente digeridos, enquanto os amidos do milho e da ervilha foram apenas parcialmente digeridos, independentemente da idade dos animais. Segundo estes mesmos autores, em animais não ruminantes, a disponibilidade do amido nos processos de digestão, depende de vários fatores, incluindo origem botânica e tratamento tecnológico. De um modo geral, o amido proveniente de cereais é mais facilmente digerido que amido oriundo de legumes. Diferenças existem também entre cereais em relação à textura do endosperma e relação amilose/amilopectina.

Dessa forma, a digestibilidade do amido consiste em uma área de intenso estudo e importância, já que os fatores pertinentes à digestão deste carboidrato são muitos. Assim, o objetivo deste trabalho foi avaliar a digestibilidade ileal e total do amido e a atividade das enzimas amilase e maltase em coelhos de duas idades ( 35 e 45 dias de vida) e alimentados com diferentes fontes de amido (milho e raspa de mandioca).

\section{Material e Métodos}

Os experimentos foram realizados no Setor de Cunicultura da Fazenda Experimental de Iguatemi da Universidade Estadual de Maringá, no período de 19 de setembro a 6 de outubro de 2000. Foram utilizados em cada experimento 20 coelhos da raça Nova Zelândia Branco, dez machos e dez fêmeas, com 35 (experimento 1) e 45 dias de idade (experimento 2), desmamados aos 28 dias, alojados individualmente em gaiolas de arame galvanizado, providas de bebedouro automático e comedouro semi-automático de chapa galvanizada, localizados em galpão de alvenaria, com cobertura de telha de fibrocimento, pé direito de 3,5 metros, piso de alvenaria, paredes laterais de 0,3 metros em alvenaria e o restante em tela e cortina de plástico para controle de ventos. A temperatura média registrada no período experimental foi de $25^{\circ} \mathrm{C}$, sendo que a máxima registrada foi de $34^{\circ} \mathrm{C}$ e a mínima, $16^{\circ} \mathrm{C}$.

As rações utilizadas nos experimentos foram constituídas de milho e a raspa de mandioca, as quais constituíram as fontes principais de amido das rações. O fornecimento das rações e da água foi à vontade. A composição percentual e química das rações experimentais encontra-se na Tabela 1.

O período experimental, em cada ensaio, teve duração de sete dias para adaptação dos animais às instalações e dietas, sendo que nos últimos quatro dias, avaliou-se o consumo de ração e coletou-se as fezes para determinação dos coeficientes de digestibilidade total do amido.

Ao final dos ensaios de digestibilidade, todos os animais foram abatidos pelo método de atordoamento, seguido de sangria pela veia jugular, retirada das patas, cauda, pele e cabeça. Imediatamente após o abate, foi retirado cerca de $20 \mathrm{~cm}$ do íleo terminal, excluindo os últimos $5 \mathrm{~cm}$ que se aproximavam da válvula ileocecal e de $20 \mathrm{~cm}$ da região após a alça duodenal (início do jejuno). Os abates foram realizados entre 8 e $10 \mathrm{~h}$. Os conteúdos ileal e do jejuno foram retirados e acondicionados em tubos plásticos em congelador a $-20^{\circ} \mathrm{C}$, para posterior liofilização.

O material liofilizado foi utilizado para determinação da atividade das enzimas amilase e maltase. A atividade da amilase foi mensurada através da incubação da amostra convenientemente diluída, em Tampão Fosfato, 50 mM, pH 6, com amido $1 \%$ (Tampão Fosfato, $50 \mathrm{mM}$, pH 6) por 10 min em banho-maria a $37^{\circ} \mathrm{C}$. Os açúcares redutores produzidos foram determinados pelo método do ácido 3,5-dinitrosalicílico (Miller, 1959). A atividade da malase foi mensurada através da incubação da amostra diluída em Tampão Fosfato, $50 \mathrm{mM}, \mathrm{pH}$ 6, com maltose $1 \%$ (Tampão Fosfato, $50 \mathrm{mM}$, pH 6) por 10 min em banho-maria à $37^{\circ} \mathrm{C}$. A glicose liberada foi mensurada com a utilização do kit enzimático Glicose PAP Liquiformâ (Cat. 84-2/500, Labtest Diagnóstica S.A., Lagoa Santa, MG, Brasil). Os resultados são apresentados como micromoles de glicose produzido por miligrama de amostra por minuto ( $\mathrm{mmol}$ de glicose $/ \mathrm{mg} / \mathrm{min}$ ). A atividade da enzima maltase foi mensurada apenas para os animais com 35 dias de idade porque a quantidade de material disponível foi insuficiente para realização de todas as análises.

Os cálculos dos coeficientes de digestibilidade aparente do amido foram realizados pelo método 
Tabela 1 - Composição percentual e química das rações experimentais (base MN)

Table 1 - Chemical and percentual composition of experimental rations (as fed basis)

\begin{tabular}{|c|c|c|}
\hline \multirow[t]{2}{*}{$\begin{array}{l}\text { Ingredientes } \\
\text { Ingredients }\end{array}$} & \multicolumn{2}{|c|}{$\begin{array}{c}\text { Tratamentos } \\
\text { Treatments }\end{array}$} \\
\hline & $\begin{array}{l}\text { Milho } \\
\text { Corn }\end{array}$ & $\begin{array}{l}\text { Raspa de mandioca } \\
\text { Cassava }\end{array}$ \\
\hline Milho & 39,50 & 0,00 \\
\hline Corn & & \\
\hline $\begin{array}{l}\text { Raspa de mandioca } \\
\text { Cassava }\end{array}$ & 0,00 & 34,80 \\
\hline $\begin{array}{l}\text { Feno de coast cross } \\
\text { Coast cross hav }\end{array}$ & 36,11 & 35,25 \\
\hline $\begin{array}{l}\text { Farinha de vísceras } \\
\text { Visceras meal }\end{array}$ & 14,57 & 18,50 \\
\hline $\begin{array}{l}\text { Casca de arroz } \\
\text { Ricepeel }\end{array}$ & 4,70 & 4,62 \\
\hline $\begin{array}{l}\text { Sal } \\
\text { Salt }\end{array}$ & 0,40 & 0,40 \\
\hline $\begin{array}{l}\text { Fosfato bicálcico } \\
\text { Dicalcium phosphate }\end{array}$ & 0,90 & 1,00 \\
\hline $\begin{array}{l}\text { Calcário } \\
\text { Limestone }\end{array}$ & 0,39 & 0,00 \\
\hline $\begin{array}{l}\text { DL-Metionina } \\
\text { DL-Metionine }\end{array}$ & 0,08 & 0,12 \\
\hline $\begin{array}{l}\text { L-Lisina HCL } \\
\text { L-Lysine HCL }\end{array}$ & 0,34 & 0,30 \\
\hline $\begin{array}{l}\text { Antioxidante } \\
\text { Antioxidant }\end{array}$ & 0,01 & 0,01 \\
\hline $\begin{array}{l}\text { Mist. Vit }+ \text { Min }^{1} \\
\text { Vit. and Min. Supplement }{ }^{1}\end{array}$ & 0,50 & 0,50 \\
\hline $\begin{array}{l}\text { Oleo vegetal } \\
\text { Vegetable oil }\end{array}$ & 2,00 & 4,00 \\
\hline Óxido crómico & 0,50 & 0,50 \\
\hline $\begin{array}{l}\text { Amido }^{2}, \% \\
\text { Starch }^{2}\end{array}$ & 26,62 & 27,10 \\
\hline $\begin{array}{l}\text { Proteína bruta, \% } \\
\text { Crude protein }\end{array}$ & 14,87 & 14,79 \\
\hline $\begin{array}{l}\text { Energia digestível }(\mathrm{Kcal} / \mathrm{Kg}) \\
\text { Digestible energy }\end{array}$ & 2253 & 2183 \\
\hline Fibra bruta, \% & 13,81 & 13,97 \\
\hline $\begin{array}{l}\text { Crude fiber } \\
\text { P total, \% }\end{array}$ & 0,51 & 0,50 \\
\hline Total P & & \\
\hline $\mathrm{Ca}(\%)$ & 0,81 & 0,81 \\
\hline Lisina, $\%$ & 0,77 & 0,78 \\
\hline $\begin{array}{l}\text { Lysine } \\
\text { Met.+Cis. (\%) }\end{array}$ & & \\
\hline $\begin{array}{l}\text { Met. }+ \text { Cis. }(\%) \\
\text { Óxido crômico } 2 . \%\end{array}$ & 0,60 & 0,61 \\
\hline $\begin{array}{l}\text { Óxido crômico }{ }^{2}, \% \\
\text { Chromic oxid }\end{array}$ & 0,36 & 0,38 \\
\hline $\mathrm{Na}(\%)$ & 0,23 & 0,26 \\
\hline
\end{tabular}

${ }^{1}$ Composição por quilo ( ${ }^{1}$ Composition per kg): Vit A., 300.000UI; Vit. D3, 50.000Ul; Vit. E, 4.000 mg; Vit K3, 100 mg; Vit B1, 200 mg; Vit B2, 300 mg; Vit B6, 100 mg; Vit. B12, 1.000 mg; Ácido nicotínico (Nicotinic ac.), 1.500 mg; Ácido pantotênico (Panthotenic ac.), $1.000 \mathrm{mg}$; Colina (Choline), $35.000 \mathrm{mg}$; Fe, $4.000 \mathrm{mg}$; Cu, $600 \mathrm{mg}$; Co, $100 \mathrm{mg}$; Mn, 4.300 mg; Zn, 6.000 mg; I, 32 mg; Se, 8 mg; Met, (Meth), 60.000 mg; Promotor de crescimento (Growth promoter), 1.500 mg; Coccidiostático (Coccidiostat), $12.500 \mathrm{mg}$; Antioxidante (Antioxidant), $10.000 \mathrm{mg}$.

2 Valores obtidos (percentagem da matéria seca) no Laboratório de Alimentos e Nutrição Animal do Departamento de Zootecnia da UEM

2 Obtained values (pergentage of dry mater) from Food and Animal Nutrition Laboratory of Animal Science Department of UEM 
indireto, que consiste na utilização de indicadores indigestíveis, como o óxido crômico $\left(\mathrm{Cr}_{2} \mathrm{O}_{3}\right)$, como descrito por Thiré (1986).

As análises de matéria seca e de óxido crômico das rações, fezes e conteúdo do íleo foram feitas de acordo com a metodologia descrita em Silva (1990).

O amido das amostras do conteúdo ileal e das fezes, bem como das rações experimentais foi mensurado, segundo o método enzimático proposto por Poore et al. (1989), adaptado por Pereira \& Rossi (1995).

Os animais foram distribuídos em delineamento experimental inteiramente casualizado, com dez repetições, sendo a unidade experimental constituída por um animal.

Os coeficientes de digestibilidade parcial e total do amido e a atividade das enzimas amilase e maltase foram analisados de acordo com o modelo:

$$
Y_{i j k l}=u+A_{i}+I_{j}+S_{k}+A_{i j} I_{j}+e_{i j k l}
$$

em que: $Y_{i j k l}=$ variável considerada de cada indivíduo $\mathrm{k}$, recebendo a fonte de amido $\mathrm{i}$, na idade $\mathrm{j}$; $\mathrm{u}=$ média geral da variável; $\mathrm{A}_{\mathrm{i}}=$ efeito da fonte de amido $\mathrm{i} ; \mathrm{I}_{\mathrm{j}}=$ efeito da idade $\mathrm{j} ; \mathrm{S}_{\mathrm{k}}=$ efeito do sexo $\mathrm{k}$; $\mathrm{A}_{\mathrm{i}} \mathrm{I}_{\mathrm{j}}=$ efeito da interação entre a fonte de amido e a idade do animal; e $\mathrm{e}_{\mathrm{ijkl}}=$ erro aleatório associado a cada observação $Y_{\mathrm{ijkl}}$.

Os resultados foram analisados pelo programa SAEG versão 7.1 (UFV, 1997). Para as variáveis em estudo, os dados foram interpretados por meio de análises de variância, considerando-se significativo $\mathrm{P}<0,05$.

\section{Resultados e Discussão}

Não foram observados efeitos significativos $(\mathrm{P}>0,05)$ de tratamento, idade e sexo sobre a ingestão de ração, durante o período experimental. A média geral obtida foi de $259,1 \pm 8,5 \mathrm{~g}$.

Os coeficientes de digestibilidade ileal (CDILEAL) e total (CDTOTAL) do amido proveniente do milho e da raspa de mandioca encontram-se na Tabela 2.

Não foi observado efeito significativo $(\mathrm{P}>0,05)$ da idade dos animais sobre o CDILEAL do amido. O CDILEAL do amido da raspa de mandioca $(59,25 \pm 1,38 \%)$ foi superior $(\mathrm{P}<0,05)$ ao do amido do milho $(54,21 \pm 1,51 \%)$. Foi verificado efeito do sexo, onde os machos apresentaram maior $(\mathrm{P}<0,05)$ CDILEAL do amido $(59,32 \pm 1,40 \%)$ que as fêmeas $(54,14 \pm 1,49 \%)$.

O CDTOTAL do amido dos animais com 45 dias de idade $(99,75 \pm 0,04 \%)$ foi estatisticamente superior $(\mathrm{P}<0,05)$ àqueles dos animais com 35 dias

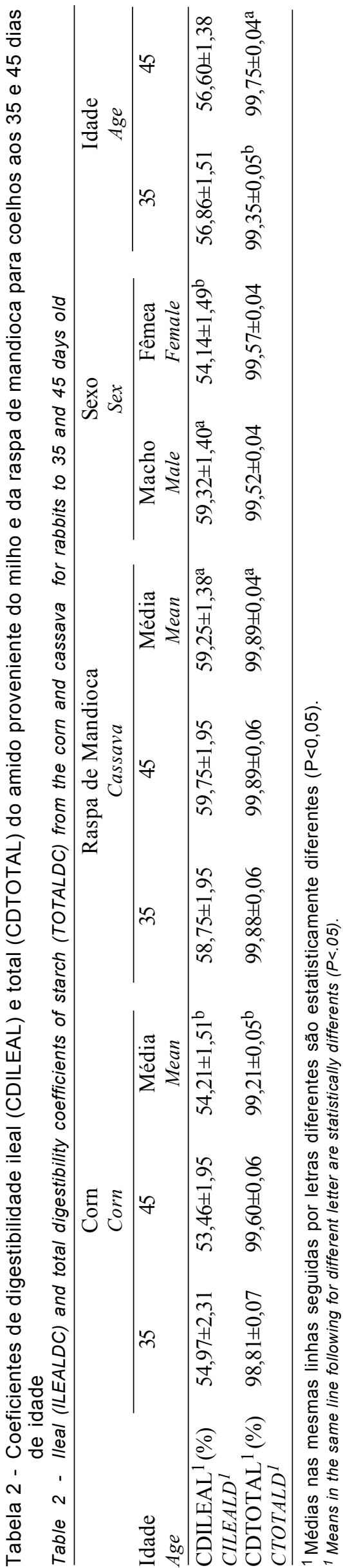

R. Bras. Zootec., v.31, n.3, p.1434-1441, 2002 (suplemento) 
$(99,35 \pm 0,05 \%)$. Semelhante ao ocorrido com o CDILEAL, o CDTOTAL do amido da raspa de mandioca $(99,89 \pm 0,04 \%)$ foi maior $(\mathrm{P}<0,05)$ que o do milho $(99,21 \pm 0,05 \%)$.

De acordo com Blas \& Gidenne (1998), a cutícula que reveste o grão de milho é um dos fatores que faz com que haja redução na digestibilidade do amido, visto que esta cutícula protege as moléculas de amido das enzimas amilolíticas. Assim, a sua remoção, através do maior grau de moagem, por exemplo, pode aumentar a área de exposição do amido às enzimas e conseqüentemente, melhorar a digestibilidade.

Os grânulos de amido da mandioca, por não se apresentarem envolvidos por cutícula, são mais facilmente moídos e ficam mais expostos à ação das enzimas amilolíticas, acarretando desta maneira, maior digestibilidade em relação ao milho.

O amido proveniente da raspa de mandioca é muito semelhante, em termos de solubilidade, ao amido purificado, e isto faz com que as perdas fecais sejam muito baixas, independentemente da idade. No entanto, segundo Gidenne \& Perez (1993), as perdas de amido provenientes do milho são grandes entre 28 e 33 dias, mas diminuem significativamente entre 49 e 54 dias de vida.

Outro fator que contribui para a diminuição das perdas fecais de amido em animais mais velhos é o aumento da atividade de algumas enzimas, como amilase e maltase (Scapinello et al., 1999).

A relação amilose/amilopectina existente no grânulo de amido também influencia a digestibilidade.

Lee et al. (1985) obtiveram, in vitro, hidrólise superior para o amido de mandioca em relação ao amido rico em amilose. Kabir et al. (1998) observaram que grânulos de amido contendo $32 \%$ de amilose também tiveram hidrólise, in vitro, inferior ao dos grânulos contendo $5 \%$.

A maior capacidade de expansão do amido da mandioca em relação ao amido do milho pode estar relacionada à menor quantidade de amilose, ao fato de a amilose estar presente apenas na região amorfa (formando menos pontes de hidrogênio com a amilopectina) e à menor formação de complexos lipídeos-amilose (Zeoula \& Caldas Neto, 2001). Segundo Brasil - MAA (2000), a farinha de mandioca apresenta apenas pequena percentagem de extrato etéreo em sua composição $(0,3 \%)$ em relação ao grão de milho $(3,7 \%)$, o que colabora para o fato de $\mathrm{o}$ amido da mandioca apresentar maior digestibilidade total que o do milho.

R. Bras. Zootec., v.31, n.3, p.1434-1441, 2002 (suplemento)
De acordo com Rooney \& Pflugfelder (1986), a região cristalina ou micelar é primeiramente composta de amilopectina, sendo esta a principal responsável pela organização desta área. A área cristalina apresenta uma maior resistência à entrada de água e, conseqüentemente, à atividade enzimática. A região amorfa é rica em amilose e menos densa que a área cristalina. Devido à menor densidade, a água se move livremente através desta região e a atividade hidrolítica das amilases, em geral, inicia-se nesta região. Dessa forma, aparentemente uma maior proporção de amilose na molécula de amido proporcionaria melhor atividade hidrolítica. Contudo, o que ocorre na realidade é uma diminuição na hidrólise do amido e, conseqüentemente, da digestibilidade de fontes de amido com maior teor de amilose, devido à maior formação de pontes de hidrogênio.

O valor médio obtido para a digestibilidade total do amido encontrado neste experimento $(99,55 \pm 0,03 \%)$ está muito próximo da média obtida por Gidenne (1992), De Blas et al. (1995) e Gidenne \& Jehl (1996), evidenciando a confiabilidade dos resultados.

Em contrapartida, o valor médio obtido para digestibilidade ileal do amido $(56,73 \pm 1,02 \%)$ é inferior ao obtido por Gidenne (1992) $(95,3 \pm 1,8 \%)$.

Os valores obtidos (média \pm desvio padrão) para a atividade específica das enzimas amilase e maltase para os coelhos alimentados com as duas fontes de amido avaliadas encontram-se na Tabela 3.

Não foram observadas diferenças $(\mathrm{P}>0,05)$ na atividade da enzima amilase no jejuno e íleo para os coelhos alimentados com milho ou raspa de mandioca, independentemente da idade.

Contudo, a atividade média da enzima amilase (ATAM) no conteúdo do jejuno foi maior $(\mathrm{P}<0,05)$ nos animais com 45 que nos de 35 dias de idade $(0,952 \pm 0,118 \mathrm{mmol}$ de glicose $/ \mathrm{mg} / \mathrm{min}$ vs $0,469 \pm 0,111$ $\mathrm{mmol}$ de glicose $/ \mathrm{mg} / \mathrm{min})$. No conteúdo ileal, também houve superioridade $(\mathrm{P}<0,05)$ na ATAM dos animais mais velhos $(0,647 \pm 0,093 \mathrm{mmol}$ de glicose $/ \mathrm{mg} / \mathrm{min}$ vs $0,375 \pm 0,088 \mathrm{mmol}$ de glicose $/ \mathrm{mg} / \mathrm{min}$ ).

A atividade da enzima maltase (ATMAL), no jejuno, foi maior nos animais alimentados com raspa de mandioca que naqueles que receberam milho $(0,061 \pm 0,007 \mathrm{mmol}$ de glicose $/ \mathrm{mg} / \mathrm{min}$ vs $0,032 \pm 0,07$ $\mathrm{mmol}$ de glicose $/ \mathrm{mg} / \mathrm{min}$ ).

Estes resultados para atividade da enzima amilase no jejuno e íleo concordam com os de Scapinello et al. (1999), que observaram maior atividade desta enzima em animais com 42 dias de idade em relação aos de 32 
Tabela 3 - Atividade específica das enzimas amilase e maltase em coelhos de 35 e 45 dias de idade e alimentados com duas fontes de amido de acordo com a região do intestino delgado

Table 3 - Specific activity of amylase and maltase enzyme in 35 and 45 days old rabbits fed with two sources of starch according to small intestine place

\begin{tabular}{|c|c|c|c|c|}
\hline & \multicolumn{2}{|c|}{$\begin{array}{c}\text { Jejuno } \\
\text { Jejunum }\end{array}$} & \multicolumn{2}{|c|}{$\begin{array}{l}\text { Íleo } \\
\text { Ileum }\end{array}$} \\
\hline & 35 & 45 & 35 & 45 \\
\hline \multirow{7}{*}{$\begin{array}{l}\text { Milho } \\
\text { Corn } \\
\text { Raspa de mandioca } \\
\text { Cassava } \\
\text { Média } \\
\text { Mean }\end{array}$} & \multicolumn{4}{|c|}{$\begin{array}{l}\text { Atividade específica da enzima amilase }(\mathrm{mmol} \text { de glicose } / \mathrm{mg} / \mathrm{min})^{1} \\
\text { Specific activity of amylase enzyme }(\mathrm{mmol} \text { de glucose } / \mathrm{mg} / \mathrm{min})^{1}\end{array}$} \\
\hline & $0,466 \pm 0,157$ & $0,974 \pm 0,166$ & $0,298 \pm 0,124$ & $0,659 \pm 0,131$ \\
\hline & & & & \\
\hline & $0,473 \pm 0,157$ & $0,929 \pm 0,166$ & $0,451 \pm 0,124$ & $0,636 \pm 0,131$ \\
\hline & & & & \\
\hline & $0,469 \pm 0,111^{b}$ & $0,952 \pm 0,118^{a}$ & $0,375 \pm 0,088^{\mathrm{a}}$ & $0,647 \pm 0,093^{b}$ \\
\hline & \multicolumn{4}{|c|}{$\begin{array}{l}\text { Atividade específica da enzima maltase }(\mathrm{mmol} \text { de glicose } / \mathrm{mg} / \mathrm{min})^{2} \\
\text { Specific activity of maltase enzyme }(\mathrm{mmol} \text { de glucose } / \mathrm{mg} / \mathrm{min})^{2}\end{array}$} \\
\hline Milho & $0,032 \pm 0,007^{b}$ & - & $0,007 \pm 0,003$ & - \\
\hline $\begin{array}{l}\text { Corn } \\
\text { Raspa de mandioca } \\
\text { Cassava }\end{array}$ & $0,061 \pm 0,007^{\mathrm{a}}$ & - & $0,014 \pm 0,003$ & - \\
\hline
\end{tabular}

dias. Todavia, Dojanã et al. (1998) não verificaram variação da atividade específica da amilase pancreática entre os 15 e 43 dias de idade em coelhos. Estas diferenças talvez possam ser explicadas, em parte, pela metodologia utilizada, já que Dojanã et al. (1998) realizaram a medida da amilase obtida diretamente no pâncreas, enquanto que Scapinello et al. (1999) analisaram a atividade no material presente no intestino dos animais, metodologia esta, utilizada no presente experimento.

A maior capacidade de digestão do amido observada nos animais mais velhos está altamente relacionada ao desenvolvimento do sistema enzimático. Como observado no presente experimento e no de Scapinello et al. (1999), o sistema enzimático encontra-se mais desenvolvido nos animais acima de 42 dias de idade. Arruda et al. (2000) também sugeriram maiores atividades das enzimas amilolíticas nos animais com 40 dias de idade.

Foi observada diferença significativa $(\mathrm{P}<0,05)$ entre a ATMAL no jejuno e no íleo, verificando-se menor atividade neste último $(0,046 \pm 0,004 \mathrm{mmol}$ de glicose/ $\mathrm{mg} / \mathrm{min}$ vs 0,011 $\pm 0,004 \mathrm{mmol}$ de glicose $/ \mathrm{mg} / \mathrm{min}$ ).

De acordo com Marounek et al. (1995), existem diferenças na atividade de algumas enzimas em função da região do trato gastrintestinal que se considera.

O suco pancreático contendo as enzimas respon- sáveis pela digestão do amido é lançado no lúmen intestinal através do ducto pancreático, na região central da alça duodenal. A partir deste ponto, as enzimas iniciam a sua atividade, ocorrendo redução gradativa, à medida que o conteúdo intestinal passa para as regiões mais distais, em função de sofrerem degradação e perda de sua atividade biológica devido às variações na concentração do substrato e nas características do meio.

Scapinello et al. (1999) também detectaram diminuição da atividade específica da amilase e da maltase à medida que o material percorria o intestino delgado. Estes resultados confirmam as observações feitas por Dojanã et al. (1998), em que a atividade da maltase diminui, à medida que a digesta passava para as regiões mais distais do trato. Os resultados apresentados nesta pesquisa estão de acordo com os descritos na literatura.

Observou-se que, no momento da realização das coletas, alguns animais apresentavam grande quantidade de digesta, enquanto outros, pouco conteúdo intestinal, certamente em função do tempo transcorrido entre a última alimentação de cada coelho e o abate.

Como verificado no presente experimento, os animais mais velhos apresentaram maior capacidade de digestão do amido. $\mathrm{O}$ amido da raspa de mandioca apresentou maior digestibilidade ileal e total quando comparado ao amido do milho. 


\section{Conclusões}

A capacidade de digestão do amido nos animais com 45 dias de idade é maior que nos animais com 35 dias. O amido da raspa de mandioca é mais digestível, tanto em nível ileal quanto total, em relação ao amido do milho. O sistema enzimático dos animais com 35 dias de idade ainda não está suficientemente desenvolvido para se otimizar a digestão do amido.

\section{Literatura Citada}

ARRUDA, A.M.V.; CARREGAL, R.D.; FERREIRA, R.G. Digestibilidade aparente de dietas contendo diferentes níveis de amido para coelhos em crescimento. Revista Brasileira de Zootecnia, v.29, n.3, p.769-775, 2000.

BLAS, E.; CERVERA, C.; FERNADEZ CARMONA, J. Effect of two diets with varied starch and fiber levels on the performances of 4-7 weeks old rabbits. World Rabbit Science, v.2, n.4, p.117-121, 1994.

BLAS, E.; GIDENNE, T. Digestion of starch and sugars. In: De BLAS, C.; WISEMAN, J. (Eds.) The nutrition of the rabbit. Cambridge: CAB, 1998. p.17-38.

BRASIL - MINISTÉRIO DA AGRICULTURA E DO ABASTECIMENTO. Normas de nutrição e alimentação animal. Brasília: MA/SARC/DFPA, 2000. 152p.

De BLAS, J.C.; TABOADA, E.; MATEOS, G.G. et al. Effect of substitution of starch for fiber and fat in isoenergetic diets on nutrient digestibility and reproductive performance of rabbits. Journal of Animal Science, v.73, n.4, p.1131$1137,1995$.

DOJAnÃ, N.; COSTACHE, M.; DINISChiotu, A. The activity of some digestive enzymes in domestic rabbits before and after weaning. Animal Science, v.66, n.2, p.501$507,1998$.

GIDENNE, T. Effect of fibre level, particle size and adaptation period on digestibility and rate of passage as measured at the ileum and in the faeces in the adult rabbit. British Journal of Nutrition, v.67, n.1, p.133-146, 1992.

GIDENNE, T. Effect of fiber level reduction and glucooligosaccharide addition on the growth performance and caecal fermentation in the growing rabbit. Animal Feed Science and Technology, v.56, n.3-4, p.253-263, 1995.

GIDENNE, T. Nutritional and ontogenic factors affecting rabbit caeco-colic digestive physiology. In: WORLD RABBIT CONGRESS, 6., 1996, Toulouse. Proceedings... Toulouse: 1996. p.13-28.

GIDENNE, T.; JEHL, N. Replacement of starch by digestible fibre in the feed for the growing rabbit. 1. Consequences for digestibility and rate of passage. Animal Feed Science and Technology, v.61, n.3-4, p.183-192, 1996.

GIDENNE, T.; PEREZ, J.M. Effect of starch origin on digestion in the rabbit. 2. Starch hidrolysis in the small intestine, cell wall degradation and rate of passage measurements. Animal Feed Science and Technology, v.42, n. 3-4, p.249-257, 1993.

HECKMAN, F.W. Potato e meal in complete feed of the fattening young rabbit. Archives Geflugelzucht Kleintierk, v.36, p.182-185, 1972.

KABIR, M.; RIZKALLA, S.W.; CHAMP, M. et al. Dietary amylose-amylopectin starch content affects glucose and lipid metabolism in adipocytes of normal and diabetic rats. Journal of Nutrition, v.128, n.1, p.35-43, 1998.
LEE, P.C.; BROOKS, S.P.; KIM. O. et al. Digestibility of native and modified starches: in vitro studies with human and rabbit pancreatic amylases and in vivo studies in rabbits. Journal of Nutrition, v.115, n.1, p.93-103, 1985.

LEHNINGER, A.L.; NELSON, D.L.; COX, M.M. Carboidratos In: LEHNINGER, A.L.; NELSON, D.L.; COX, M.M. (Eds.) Princípios de bioquímica. 2.ed. São Paulo: Sarvier, 1995. p.222-241.

MAROUNEK, M.; VOVK, S.J.; SKRIVANOVA, V. Distribuition of activity of hydrolytic enzymes in the digestive tract of rabbits. British Journal Nutrition, v.73, n.3, p.463-469, 1995.

MILLER, G.L. Use of dinitrosalicylic acid reagent for determination of reducing sugar. Analytical Chemistry, v.31, n.3, p.426-428, 1959.

MOREIRA, I. Valor nutritivo e utilização do milho e soja integral processados a calor na alimentação de leitões. Viçosa, MG: Universidade Federal de Viçosa, 1993. 145p. Tese (Doutorado em Zootecnia) - Universidade Federal de Viçosa, 1993.

PEREIRA, J.R.A.; ROSSI, J.R.P. Manual prático de avaliação nutricional dos alimentos. Piracicaba: Fundação de Estudos Agrários Luiz de Queiroz, 1995. 25p.

POORE, J.R.; ECK, T.P.; SWINGLE, R.S. et al. Total starch and relative starch availability of grains. In: BIENAL CONFERENCE ON RUMEN FUNCTION, 20, 1989, Chicago. Abstract... Chicago, 1989. p.35.

ROONEY, L.W.; PFLUGFELDER, R.L. Factor affecting starch digestibility with special emphasis on sorghum and corn. Journal of Animal Science, v.63, n.5, p.1607-1623, 1986.

SCAPINELLO, C.; GIDENNE, T.; FORTUN-LAMOTHE, L. Digestive capacity of the rabbit during the post-wearning period, according to the milk/solid feed intake pattern before wearning. Reproduction Nutrition Development, v.39, n.4, p.423-432, 1999.

SILVA, D.J. Análise de alimentos (métodos químicos e biológicos). Viçosa, MG: Universidade Federal de Viçosa, 1990. $165 \mathrm{p}$.

SWINKELS, J.J.M. Sources of starch, its chemistry and physics In: Van BEYNUM, G.M.A.; ROELS, J.A. Starch conversion technology. New York: Marcel Dekker, Inc., 1985. p.15-46.

THIRÉ, M.C. Valores energéticos e digestibilidade ileal e total de aminoácidos em alimentos brasileiros, para suínos. Viçosa, MG: Universidade Federal de Viçosa, 1986. 65p. Dissertação (Mestrado em Zootecnia) - Universidade Federal de Viçosa, 1986.

UNIVERSIDADE FEDERAL DE VIÇOSA - UFV. SAEG Sistema de Análises Estatísticas e Genéticas. Viçosa: UFV, 1997. 150p. (Versão 7.1, Manual do usuário).

ZEOULA, L.M.; CALDAS NETO, S.F. Recentes avanços em amido na nutrição de vacas leiteiras. In: SINLEITE (NOVOS CONCEITOS EM NUTRIÇÃO), 2, 2001, Lavras. Anais... Lavras: Universidade Federal de Lavras, 2001. p.249-284.

ZHOU, X.; KAPLAN, M.L. Soluble amylose cornstarch is more digestible than soluble amylopectin potato starch in rats. Journal of Nutrition, v.127, n.7, p.1349-1356, 1997. 